\title{
ACTION OF ANTIHISTAMINES ON THE ENDOMETRIUM AND THE HISTAMINE THEORY OF DECIDUAL INDUCTION
}

\author{
G. TACHI, SUMIE TACHI AND H. R. LINDNER \\ Department of Biodynamics, Weizmann Institute of Science, Rehovot, Israel
}

(Received 6th April 1970)

\begin{abstract}
Summary. Intraluminal injection of pyrathiazine, promethazine and benadryl into the uterus of pseudopregnant rats at dose levels reported to suppress the decidual reaction ( $1 \mathrm{mg} / \mathrm{horn}$ ) caused extensive necrosis of the endometrium. Suppression of the decidual reaction by these agents when applied locally cannot, therefore, be attributed unequivocally to their antihistaminic properties and, hence, does not provide evidence for a rôle of histamine in the mediation of decidual induction.
\end{abstract}

Suppression of deciduoma formation by intraluminally applied antihistamine drugs (Shelesnyak, 1954, 1957) and induction of deciduomata by histamine or histamine releasers (Kraicer \& Shelesnyak, 1958) led Shelesnyak and his colleagues to propose the 'histamine theory' of decidual induction. The theory received further support from the observation that locally applied antihistamines effectively prevented the development of polyploidy characteristic of the decidual reaction to trauma (Sachs \& Shelesnyak, 1955; Shelesnyak, 1957). Among several antihistamine drugs tested, pyrathiazine was found most potent in suppressing deciduoma formation when instilled into the uterine lumen of rats. The drug was also effective when administered up to 3 days before the application of stimuli that induce deciduoma formation (Shelesnyak, 1957; Shelesnyak \& Kraicer, 1964). Local application of severe irritants, such as acetic acid or xylene, likewise prevented the decidual reaction, but the authors concluded that the inhibition of deciduoma formation by antihistamines was not due to destruction of the uterine tissue (Sachs \& Shelesnyak, 1955; Shelesnyak, 1957). However, none of the antihistamine drugs tested was effective in suppressing deciduoma formation when administered by a systemic route.

Some phenothiazine derivatives (Seeman \& Weinstein, 1966; Seeman, 1966), including pyrathiazine (G. Tachi, unpublished observation), are haemolytic at high concentration (e.g. $>10^{-3}$ M-pyrathiazine or promethazine), suggesting that such drugs may act on the endometrial cells as non-specific membranolytic agents, in a manner unrelated to their antihistaminic properties. To test this hypothesis, we examined the histological and ultrastructural appearance of the endometrium of rats following intraluminal administration of two antihistaminic phenothiazine derivatives. 
Wistar-derived, 100-day-old, female albino rats of the Biodynamics Institute colony were used. Pseudopregnancy was induced by electrical stimulation of the cervix (Shelesnyak, 1931). On the 2nd and 4th day of leucocytic smear, referred to as Days $L_{2}$ and $L_{4}$ of pseudopregnancy, respectively, the animals were anaesthetized with ether and the uterus was exposed by laparotomy. A solution of an antihistamine drug $(0.1 \mathrm{ml})$ was slowly injected into the lumen through a No. 27 gauge needle inserted from the uterotubal junction. The following antihistamine agents were dissolved in glass-distilled water immediately before use at the concentration specified in the text: pyrathiazine hydrochloride, 10-(2-(1-pyrrolidyl)ethyl)-phenothiazine hydrochloride (Pyrrolazote, Upjohn); promethazine hydrochloride, 10-(2-dimethylaminopropyl)phenothiazine hydrochloride (Phenergan, May and Baker); benadryl (2diphenyl-methoxy- $\mathcal{N}, \mathcal{N}$-dimethylethylamine (Diphenhydramine, Teva).

For selection of dose levels and method of local application of the drugs, we followed the description of Shelesnyak (1957). The stated dose levels were based on the weight of the salts. Control horns, contralateral to the experimental ones, were injected with $0.1 \mathrm{ml}$ glass-distilled water.

The animals were re-anaesthetized $4 \mathrm{hr}$ after laparotomy and the uteri were fixed in situ by perfusion (Tachi, Tachi \& Lindner, 1969) with $3 \%$ glutaraldehyde (Sabatini, Bensch \& Barrnett, 1963). When examination by light microscopy only was intended, the excised uteri were fixed in Bouin's solution. For electron microscopy, specimens obtained from the uteri fixed in situ were postfixed in $1 \% \mathrm{OsO}_{4}$ (Millonig, 1961) and embedded in Araldite resin (Fluka). Thin sections were stained with lead hydroxide (Karnovsky, 1961) and examined with an RGA EMU 2A electron microscope.

Administration of $1 \mathrm{mg}$ pyrathiazine/uterine horn in $0.1 \mathrm{ml}$ of glass-distilled water on either Day $L_{2}$ or $L_{4}$ invariably caused severe endometrial cell damage (Pl. 1, Fig. 1). This dose of pyrathiazine was found by Shelesnyak (1957) to inhibit decidual induction. All the epithelial cells had vanished and most of the subepithelial cells were disrupted. Massive haemorrhage and leucocytic infiltration were frequently observed in the subepithelial region. The lower dose of pyrathiazine $(0.1 \mathrm{mg}$ in $0.1 \mathrm{ml} /$ horn $)$, which is not inhibitory to deciduoma formation, caused little histologically demonstrable damage (PI. 1, Fig. 2).

The endometrium of the control horns which received only distilled water showed no histological abnormality.

\section{EXPLANATION OF PLATE 1}

Appearance of endometrium $4 \mathrm{hr}$ after intraluminal instillation of pyrathiazine hydrochloride on Day $\mathrm{L}_{2}$ of pseudopregnancy. Abbreviations: BM, basement membrane; $\mathrm{C}$, capillary; $\mathrm{E}$, epithelium; ED, epithelial cell débris; $\mathrm{G}$, gland; $\mathrm{L}$, lumen; $N$, nucleus; $\mathrm{RG}$, erythrocyte.

FIG. 1. Dose level $1 \mathrm{mg} /$ horn. Note disappearance of columnar epithelial cells and necrosis in the stroma. Haemorrhage and leucocytic infiltration are present in the necrotic areas. $\times 130$.

Frg. 2. Dose level $0.1 \mathrm{mg} /$ horn. Note intact epithelial cells and normal appearance of stroma and endometrial glands. $\times 130$.

Fig. 3. Dose level $1 \mathrm{mg} /$ horn, electron micrograph. Note complete elimination of epithelial cells and destruction of the subepithelial stromal cells. The basement membrane persists. Extravasated erythrocytes are common. The scale marking represents $5 \mu$. 

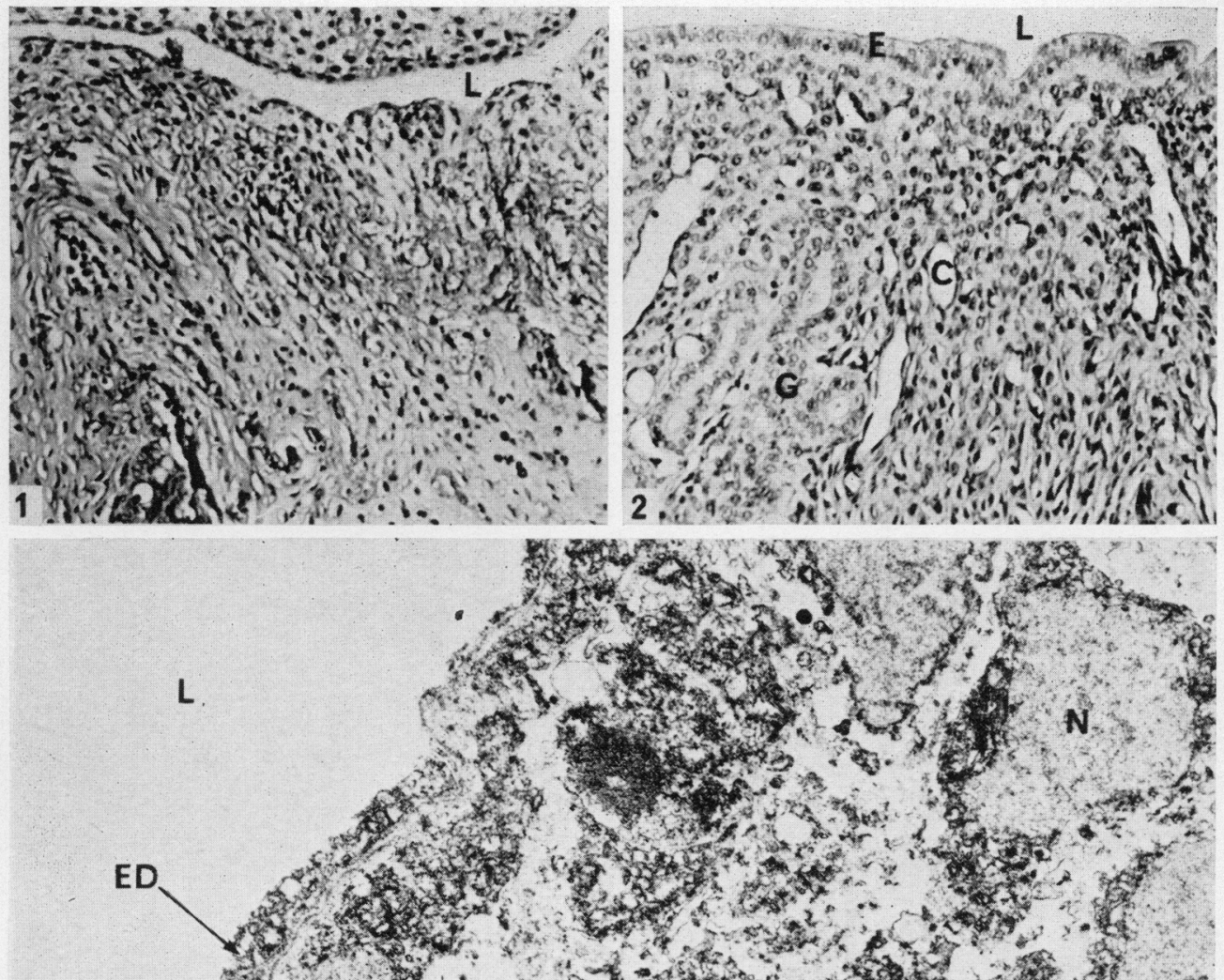

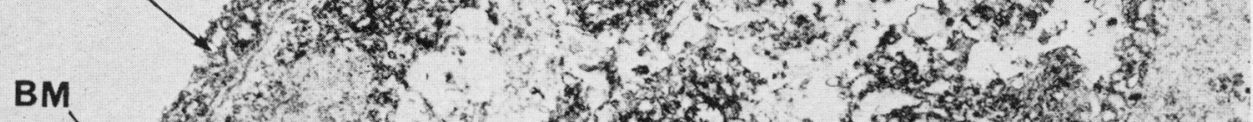

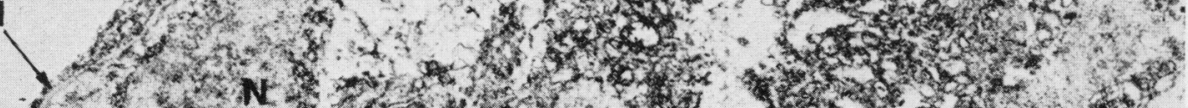

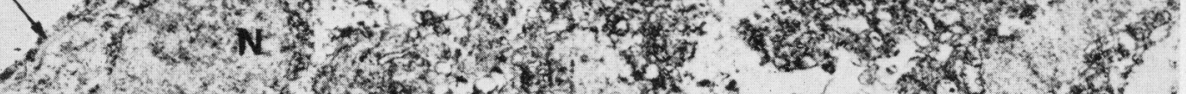

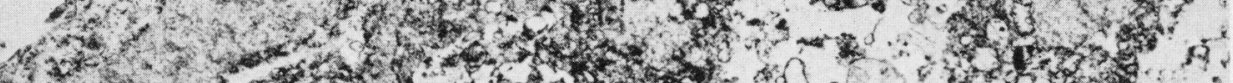

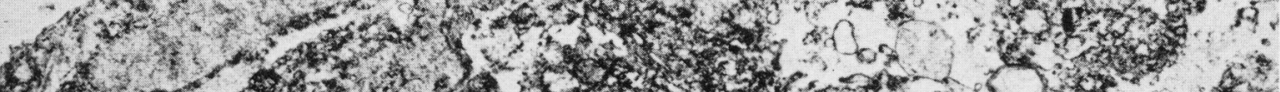

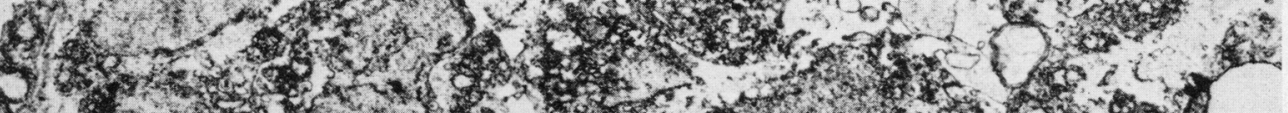

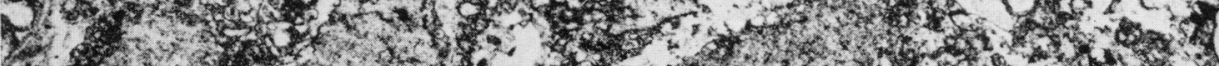

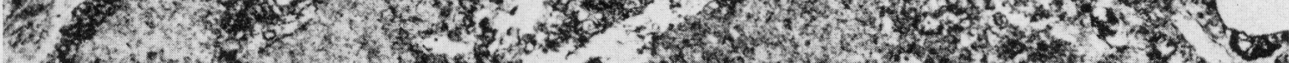

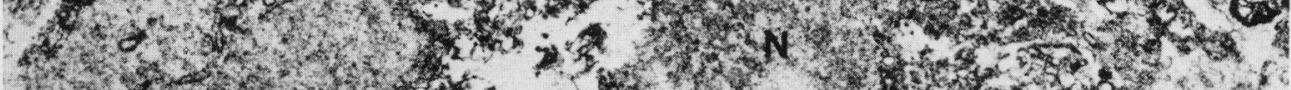

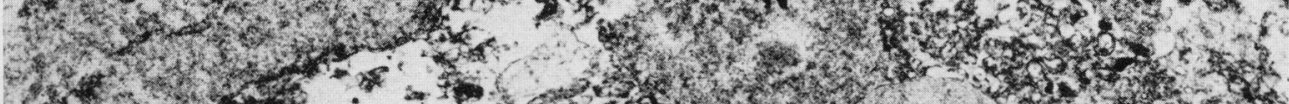

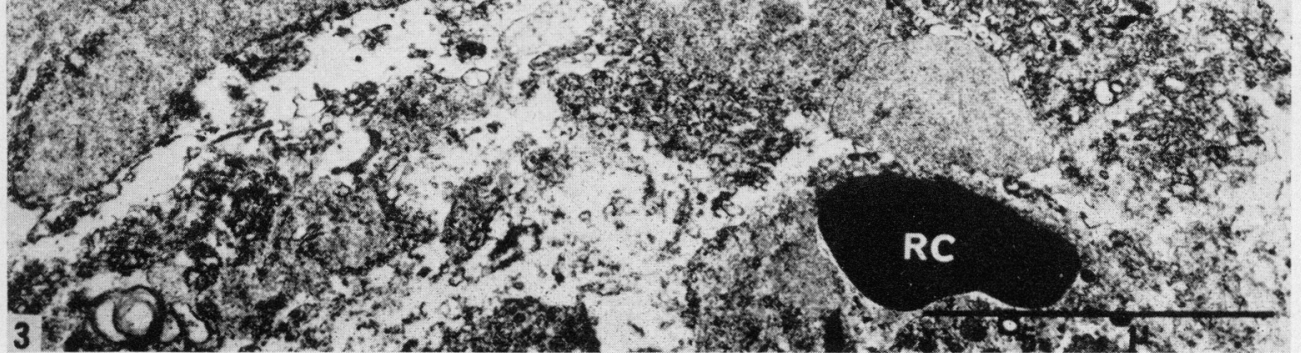


A representative electron micrograph of the epithelial and subepithelial regions of the endometrium after intraluminal injection of pyrathiazine at the dose inhibitory to deciduoma formation is shown in Pl. 1, Fig. 3. The epithelial cells are entirely eliminated and the remaining basement membrane demarcates the subepithelial stromal region from the lumen. The subepithelial stromal cells are disrupted and fragmented. Remnants of nuclei are scattered in the area. In other specimens, ruptured capillaries were seen. However, the cells which are located deeper in the endometrial stroma toward the myometrium did not appear to be affected.

Regeneration of the destroyed endometrium was not complete $24 \mathrm{hr}$ after the instillation. Although epithelial cells had spread from the glandular openings to form a flat cover over part of the luminal surface, the endometrium was haemorrhagic and infiltrated with leucocytes and still showed extensive areas of injury or necrosis.

Promethazine, at a dose level inhibitory to deciduoma formation $(1 \mathrm{mg}$ in $0.1 \mathrm{ml} /$ horn), likewise caused massive destruction of the epithelial and subepithelial regions of the endometrium. Occasionally, however, the destruction was only partial and did not extend along the entire horn. The lower, non-inhibitory dose of the drug $(0.1 \mathrm{mg}$ in $0.1 \mathrm{ml} / \mathrm{horn})$ left the endometrium histologically unaffected in both $\mathrm{L}_{2}$ and $\mathrm{L}_{4}$ uteri.

Pyrathiazine and promethazine belong to the same category of phenothiazine derivatives. On the other hand, benadryl is chemically unrelated to phenothiazine, though its effectiveness in suppressing deciduoma formation is equal to that of promethazine and slightly less than that of pyrathiazine (Shelesnyak, 1957). Benadryl also caused intense endometrial damage at the dose of $1 \mathrm{mg}$ in $0.1 \mathrm{ml} /$ horn. The extent of the damage, however, appeared to be less pronounced than that observed after administration of either pyrathiazine or promethazine. In the endometrium treated with a non-inhibitory dose of the drug $(0.1 \mathrm{mg}$ in $0.1 \mathrm{ml} /$ horn), strong leucocytic infiltration was observed.

Suppression of the decidual induction by antihistaminics applied directly to the uterine lumen thus appears to be correlated with the presence of endometrial damage, although in the case of benadryl the visible damage was relatively moderate. Parr (1969) observed a strong inflammatory reaction in the uterus 3 days after injection of antihistamine drugs into the lumen and concluded that their inhibitory effect on decidual induction is due to inflammation and not to specific antihistaminic activity. The damage described by us $4 \mathrm{hr}$ after local antihistamine administration was of a different type, but leads to similar reservations with regard to the interpretation of experiments based on local application of antihistamines. Humphrey \& Martin (1968) likewise noted evidence of tissue damage following intraperitoneal administration of pyrathiazine to mice.

The view that histamine is one of the mediators involved in deciduoma induction is not necessarily invalidated by the present observations. They indicate, however, that the results of intraluminal administration of antihistaminic drugs cannot be accepted as independent evidence for the histamine theory of decidual induction. For this type of experiment, an antihistaminic compound with minimal surface-active potency may be required. 
This work was supported by the Ford Foundation and the Population Council, New York. It was carried out in partial fulfilment of the requirements for the Ph.D. degree of the Weizmann Institute's Graduate School (G.T. and S.T.).

\section{REFERENCES}

Humphrey, K. W. \& Martin, L. (1968) Attempted induction of deciduomata in mice with mast-cell, capillary permeability and tissue inflammatory factors. F. Endocr. 42, 129.

Karnovsky, M. J. (1961) Simple methods for staining with lead at high pH in electron microscopy. 7. biophys. biochem. Cytol. 11, 729.

Kraicer, P. F. \& Shelesnyak, M. C. (1958) The induction of deciduomata in the pseudopregnant rat by systemic administration of histamine and histamine releasers. $\mathcal{7}$. Endocr. 17, 324.

Millonig, G. (1961) Advantage of phosphate buffer for $\mathrm{OsO}_{4}$ solutions in fixation. F. appl. Physiol. 32, 1637.

PARR, E. (1969) The role of uterine inflammation in the inhibition of decidualization by intraluminal antihistamines. Biol. Reprod. 1, 258.

Sabatini, D. D., Bensch, K. G. \& Barrnett, R. J. (1963) Cytochemistry and electron microscopy. The preservation of cellular ultrastructure and enzymatic activity by aldehyde fixation. 7 . Cell Biol. 17, 19.

Sachs, L. \& Shelesnyak, M. C. (1955) The development and suppression of polyploidy in the developing and suppressed deciduoma in the rat. F. Endocr. 12, 146.

Szeman, P. (1966) Membrane stabilization by drugs. Int. Rev. Neurobiol. 9, 146.

SeEman, P. \& Weinstein, J. (1966). I. Erythrocyte membrane stabilization by tranquilizers and antihistaminics. Biochem. Pharmac. 15, 1737.

Shelesnyak, M. C. (1931) The induction of pseudopregnancy in the rat by means of electrical stimulation. Anat. Rec. 49, 179.

Shelesnyak, M. C. (1954) Comparative effectiveness of antihistamines in suppression of the decidual cell reaction in the pseudopregnant rat. Endocrinology, 54, 396.

Shelesnyak, M, C. (1957) Some experimental studies on the mechanism of ova-implantation in the rat. Recent Prog. Horm. Res. 13, 269.

Shelesnyak, M. C. \& Kraicer, P. F. (1964) Studies on the mechanism of nidation, XI. Duration of the inhibition of decidual induction by antihistamine. F. Reprod. Fert. 8, 287.

TAchi, S., TACHI, G. \& Lindner, H. R. (1969) Cilia-bearing stromal cells in the rat uterus. F. Anat. 104, 295. 